\title{
Diffusion pattern of Linux: An assessment on major technology dimensions
}

By: Nir Kshetri

Kshetri, Nir (2005) “Diffusion pattern of Linux: An assessment on major technology dimensions,” First Monday, 10(8)(August).

Made available courtesy of First Monday: http://firstmonday.org/issues/issue10_8/kshetri/index.html

\begin{abstract}
:
This paper attempts to gain an understanding of the diffusion dynamics of Linux by assessing it on Rogers' technology dimensions — relative advantage, compatibility, complexity, observability, and trialability. The analysis makes clear that Linux possesses greater relative advantage than its proprietary competitors because of its low cost, lower susceptibility to bugs and crashes, resilience to obsolescence, ability to run on older machines and higher perceived security. Linux is facing compatibility problems with applications, hardware and other corporate resources; suppliers' and customers' technologies; and, skills of current and potential employees. Extreme configurability and user unfriendly interface; limited support and staff knowledge; and, potential hazard of forking into competing versions have been some major sources of Linux's complexity. Linux seems to have a reasonably good performance on observability and trialability dimensions. The paper concludes by offering some suggestions on how to accelerate the diffusion of Linux among software developers, national governments and international agencies.
\end{abstract}

Keywords: Linux | diffusion dynamics | software compatibility | software adoption

\section{Article:}

Introduction

Linux, the flagship of open source software (OSS) (Applewhite, 2003), is a significant force in strengthening the positions of some developing countries on the global technology map (Wilburn, 1997; UNCTAD, 2002). It is touted to be ideal for accelerating the growth of the IT industry in some low-income countries and is expected to increase their propensity to innovate.

Linux has been the primary source of major technological innovations originated for and used in developing countries. For instance, Encore Software of India has designed a handheld Internet appliance, Simputer, based on Linux. At a cost of below US\$200, Simputer provides Internet and e-mail access in local languages; microbanking applications; speech recognition; and, text-tospeech conversion. Time magazine described Simputer as among the best ten technological innovations of 2001. Similarly, Computador Popular (Popular Computers) in Brazil, priced at 
less than US\$250, runs Linux. Computador Popular is an Internet appliance without a floppy or a hard disk drive and features many attributes in a moderately-priced PC. Consumers can also buy inexpensive hard disks and other peripherals.

Linux's potential to bridge the global digital divide (Cat, 2001), however, has not been fully exploited. A deeper and clearer understanding of the factors facilitating and hindering the adoption of this technology would help the Linux community, software developers and policy makers to devise appropriate strategies to accelerate its diffusion, especially among those that are on the wrong side of the global digital divide.

The aim of this paper is to gain an understanding of the diffusion dynamics of Linux and offer some suggestions as to how measures can be taken at various levels to accelerate its diffusion. We attempt to achieve this objective by assessing Linux on major technology dimensions. This paper emphasizes developing countries since 81 percent of the world population living in these countries are likely to have a strong influence on the diffusion of any technology. The remainder of the paper is organized as follows. The following section examines the characteristics of a technology influencing its diffusion. Next, we assess Linux in terms of various technology dimensions. Finally, we provide some conclusions and discuss the implications.

Technology characteristics shaping the diffusion pattern: Theoretical and empirical evidence Rogers (1962, 1983) proposed five major dimensions that influence the adoption of an innovation - relative advantage, compatibility, complexity, observability and trialability. Another dimension originally added by Ostlund (1974) — the perceived risk of adoption — has received increased attention in recent years (e.g., Gatignon and Robertson, 1985; Rogers, 1995; Smith and Andrews, 1995). Perceived risk of innovation is negatively related with the evaluation of a product and its adoption rate (Smith and Andrews, 1995). A meta-analysis conducted by Tornatzky and Klein (1982) revealed 10 dimensions of innovation characteristics shaping the adoption process. Apart from the five dimensions proposed by Rogers (1962), Tornatzky and Klein found five additional dimensions: cost, communicability, divisibility, profitability and social approval. The technology acceptance model proposed by Davis (1989) argues that user perceptions of usefulness and ease of use influence the acceptance and usage of a technology.

Numerous studies have been conducted to extend the models of Rogers, Tornatztky and Klein, and Davis leading to the identification of a number of additional factors. Moore and Benbasat (1991), for instance, arrived at a classification of eight characteristics: relative advantage, 
compatibility, ease ofuse, result demonstrability, effect on the user's image, visibility, trialability and voluntariness. Of these, result demonstrability and visibility are arguably two subdimensions of Roger's observability dimension.

Loh and Ong (1998) found perceived usefulness positively related with perceived ease of use, duration of use as well as user satisfaction. Similarly, comparing the technology dimensions suggested by Rogers and Tornatzky and Klein, Wee (2003) found that communicability is correlated with Rogers' observability; and divisibility [1] and cost are related with trialability.

Studies have indicated that Davis' perceived usefulness and perceived ease of use are conceptually similar to Rogers' relative advantage and complexity. Only these and compatibility influence the adoption process (Davis, 1989; Karahanna, et al., 1999; Moore and Benbasat, 1991). There is, however, no absolute measure of ease of use or usefulness, and user perceptions of these constructs for a technology are functions of time and experience (Adams, et al., 1992). Moore and Benbasat's study found no significant effect of result demonstrability and visibility (sub-dimensions of Roger's observability) and trialability) on the adoption process.

The above discussion indicates that the characteristics of a technology that influence its diffusion can be represented by the five near-orthogonal dimensions suggested by Rogers (Table 1). Especially for relative advantage, complexity and compatibility, the theoretical prediction from Roger's model have found strong empirical support. For the remaining two dimensionsobservability and trialability, empirical support has been weak.

Table 1: Characteristics of a technology influencing its diffusion rate. Source: Frizelle (1998), Rogers $(1962,1983,1995)$ and author's research.

\section{Dimension Explanation}

Relative Perceived benefits of a technology over previous technologies and the extent to advantage which it is better than the idea it supersedes.

The degree to which a technology and the tasks it performs are perceived as

Compatibility being consistent with the existing values, beliefs, past experiences, and needs of potential adopters.

Complexity Level of difficulty of installing and using a technology (variety and uncertainty increase complexity). 
The degree to which the features and benefits of a technology are visible, Observability noticeable and understandable to self/others, the results are can be described to non-users.

Trialability The ability to experiment or try (on a limited basis) before formally adopting.

Potential adopters of a technology — individuals, companies and government agencies — are likely to differ in terms of their importance of a given dimension and their perceptions of a technology. Some possible sources of such variations include industry sector and size for companies; demographic characteristics for individuals; and, orientation toward democracy versus authoritarianism for governments. In U.S. industries, for example, cost savings (relative advantage) from B2B e-commerce - as a percent of total input costs - vary from two percent in coal to 40 percent in electronic components (Coppel, 2000). Similarly, computer engineers are likely to differ from the average population in terms of their perception of the complexity of Linux. Likewise, modern interpersonal communications such as the Internet are more compatible with democratic regimes compared to authoritarian ones (Kshetri, 2001).

Assessing Linux in terms of Rogers’ dimensions

This section evaluates Linux in terms of the technology dimensions identified earlier. Since Microsoft's Windows, used in over 90 percent of the world's desktops, is the major proprietary system that competes with Linux, we will compare Linux with Windows in terms of the technology dimensions.

Relative advantage

The first source of relative advantage for Linux is its low total cost of ownership (TCO). TCO depends upon the investment, maintenance, the cost of downtime and the cost of obsolescence. Many OSS users think that Linux has a lower TCO. A survey conducted in the U.S., Brazil, France, Germany, Sweden and Japan, for instance, indicated that 40 percent of the respondents perceived Linux as having a lower TCO.

Consider the initial investment. The price of Microsoft's entry-level operating system was US\$90 [2] in 2002. Taking US\$600 as the average price of a PC, it amounts to 15 percent of the 
total cost of a PC. Linux, on the other hand, can be freely downloaded or can be purchased for a nominal distribution fee. Compared to computer users in developed countries, these costs are much higher proportions of incomes for those in developing countries (Ghosh, 2003). Linux's cost saving potential is thus more appealing to users from developing countries. PCs with Linux as the operating system are, thus, more attractive in developing countries. LG Electronics, the South Korean multinational, for instance, sells Linux-based desktops in India at prices lower than brands using commercial operating systems.

Linux's lower susceptibility to bugs and crash compared to commercial operating systems (Ammann, 2002) also results in lower TCO by reducing downtime (a component of TCO). By harnessing "the power of natural surveillance" (Katyal, 2003) and using communications like email, bug reports, bulletin boards and various tracking mechanisms, Linux communities can capture, rearticulate and refine implicit, misstated or unstated system requirements causing bugs, missing functionality and incorrect calculation (Scacchi, 2002; Wu and Lin, 2001). Furthermore, there are no widespread viruses for Linux systems [3].

Linux is also resilient to obsolescence (another component of TCO) because of its built-in features to guard against obsolescence. Many Linux programs use text files to store data and complex formats such as gnumeric and SciGraphica use XML, which itself is a text-based format. Editors like vi and emacs are used to get data into a newer version of an application. Furthermore, the Linux kernel maintains a wide range of file systems types so that files previously stored can be easily read by modern Linux workstations.

The second source of advantage comes from its ability to run on old machines (Gray, 2000). Linux can even run on 486 processors. Microsoft Windows XP Professional, on the other hand, requires a minimum of a $233 \mathrm{MHz}$ processor and 64MB of RAM. This advantage of Linux is more important for users in developing countries. Unaffordability of new PCs and thanks to donations from developed countries, developing countries have a high proportion of computers that are used, old and "outdated". Silicon Valley Toxics Coalition's estimate suggests that 400 million computers — discarded in U.S. during 1997-2007 — will be shipped to developing countries.

The third source of advantage is related to Linux's security features. Since the security code in Linux is examined by many users and fixed at a faster rate, Linux code is likely to have fewer security flaws than an equally old proprietary code (Schneier, 1999). A study conducted by 
Rebecca Bace, Daniel Geer, Peter Gutmann, Charles P. Pfleeger, John S. Quarterman, and Bruce Schneier under the auspices of the Computer \& Communications Industry Association (CCIA) warned about security vulnerabilities in Microsoft's software (CCIANet 2003). Similarly, a comparison of Debian GNU/Linux with Sun Microsystems Solaris (a proprietary system) indicated that the former had more security features and fewer vulnerabilities than the latter (Payne, 2002). The closed nature of proprietary software is viewed by some governments as threats to national security. The Chinese government, for instance, thinks that Microsoft and the U.S. government spy on Chinese computer users through secret "back doors" embedded in Microsoft programs (Goad and Holland, 2000). Linux has become popular in China mainly because of a perception that it is more secure (Pottinger, 2003).

Microsoft's strategies in recent years have reduced Linux's relative advantage with respect to Windows. Microsoft's offer of deep discounts and even free products to institutional buyers and governments (Europemedia, 2003, The Economist, 2003) has reduced TCO-related attractiveness of Linux. Microsoft has also addressed some governments' security concerns. For instance, Microsoft opened Windows XP, Windows 2000 and other systems programs to government technical security experts of Russia, Britain and the U.S. (Menn, 2003). In February 2003, Microsoft signed an agreement to share Windows source code with the Chinese Government (SinoCast China Business Daily News, 2003).

\section{Compatibility}

Networked technologies such as Linux derive much of their value from compatibility (Katz and Shapiro, 1985, 1986, 1994; Shapiro and Varian, 1999). Katz and Shapiro [4] have pointed out three positive consumption externalities associated with compatibility: direct physical effect (utility of a network increases with its size); indirect effects such as increased amount and variety of software with higher hardware sales; and, via the availability of post-purchase services.

The degree of compatibility and the decision of a unit to adopt a technology are functions of corporate resources such as hardware, applications and existing files; and, technologies used by trading partners. The global computing market seems to have so much "inertia associated with network effects" [5] of Windows that discourages users from switching to Linux. 
First, consider operating systems-application compatibility. Although there is "partial compatibility" (de Palma, et al., 1999) between Linux and Windows, the degree of compatibility enjoyed by consumers has been very low. A few applications such as WINE and VMware can be used to run Windows applications on and within Linux. Many Linux and Windows applications, however, don't work on each other's platforms. Linux, thus, can't become widely used unless its applications become popular. Microsoft is not likely to gain from demand for hybrids (Microsoft's applications and Linux operating systems and vice versa). In a sense, Microsoft prefers incompatibility by refusing to offer its applications in versions operational directly under Linux. High costs of converting huge Word and Excel documents - costs associated with prior technological commitments (Jackson, 1985) - have further increased the inertia to stick with Windows (Business Week, 2003).

Second, Linux users are also encountering compatibility issues with business partners' standards or client needs [6]. Trading relationship between firms is a function of the degree of 'fit' of their technologies or the 'technological distance' (Ford, et al. 1998). Because of their lower bargaining powers, firms of developing countries are required to comply with those technologies used by their trading partners in advanced countries. When trading partners from developed countries follow Microsoft standards - as a large number will — firms in developing countries are less likely to adopt Linux [7]. In this aspect, Linux is attractive to governments and more so to municipalities because of their low degree of connectivity to specific firms.

Third, pervasive knowledge of Microsoft's products among corporations' current and prospective employees is making it hard to replace Windows by other products (Scannell and Trott, 1999). Even in developing countries, pirated copies (of proprietary software) are widely used. Consequently, Microsoft Office has become the de facto standard in many developing countries. Unlike the situation in developed countries, however, third-party and vendor supports, and good reference books are not widely available for Microsoft's products in developing countries in local languages.

In addition to the inertia associated with Microsoft's network effects, there are other factors that increase Linux's incompatibility. First, device drivers compatible with Linux are not necessarily available for some components, especially in developing countries. Second, Linux's possibility of forking into numerous incompatible versions (Kogut and Metiu, 2001) is likely to increase customer uncertainty and hence the lack of customer fit (Smith and Andrews, 1995) thereby increasing incompatibility [8]. 
OSS such as Linux, however, tends to be more compatible than proprietary software with the social beliefs prevalent in some developing countries. Societies in Asian countries, for instance, do not believe in the concept of the private ownership of ideas and hence either lack or do not enforce intellectual property protection (IPP) laws (Mittelstaedt and Mittelstaedt, 1997). High proportions of pirated software in these countries - 99 percent in Vietnam, 96 percent in China and Indonesia (Marron and Steel, 2000) and 97 percent in Thailand (Thurow, 1997) — are results of such beliefs.

\section{Complexity}

Compared to commercial software, a small budget for Linux projects can provide limited usability laboratories, user surveys and detailed experiments and involvement of outside experts. Linux's extreme configurability and user-unfriendly interface have increased its complexity. A Time magazine article published on 24 May 1999, described Linux’s complexity: "The [Linux] interface is user friendly only if the user happens to be a [computer science] Ph. D." However, users that have worked with Linux codes - some 15 million by 2001 (Katyal, 2003) — have worked to increase Linux's user-friendliness to extend its reach outside technical and knowledgeable individuals. Consequently, some users are perceiving Linux as becoming simpler to use (Bulkeley, 2003).

Second, limited support and staff knowledge for Linux has increased its perceived complexity. However, an increasing number of hardware and software vendors, distributors and third parties are providing supports for Linux users (Margulius, 2003).

Linux's possibility of forking into numerous versions (also discussed in the previous section on compatibility) is another source of complexity (Kogut and Metiu, 2001). Past research has found that variety and uncertainty of multiple versions increase complexity (Frizelle, 1998). There are already several commercial versions of Linux in existence including flavors distributed by Red Hat, SuSe, Turbolinux, and United Linux. If they evolve into substantially different programs, software companies that sell applications might have to develop separate versions for each type.

Observability 
The first source of observability comes from Linux's amenability to modification so that the benefits can be easily seen and understood. In OSS like Linux, users can see, patch and alter codes or add new features to fit their needs (Parish, 2003). In the language of technology transfer, this would be called a "level three" transfer (Williams and Gibson, 1990), the most "involved" form of transfer in which developers and users have shared responsibility for the application of the technology including its profitable use.

Linux's high degree of amenability to modification makes "level three" transfer feasible, and increases the understandability of results (or observability). Linux's potential observability seems to be stronger for groups ignored by proprietary software developers, such as relatively small linguistic groups, non-English speaking population and illiterate users. For example, the OSS Translation Project in South Africa (http://www.translate.org.za) has come up with Xhosa language packs for Linux to address the lack of support from Windows and Microsoft.

Similarly, Microsoft's South Asian edition had problems related to fonts. Microsoft was unaware of complex character clusters associated with consonant/vowel modifiers in Indian languages. Access to Linux codes allowed an Indian engineer to make a patch which allows the use of a single character code to display multiple glyphs. The patch has been extended to "load userdefined, context-sensitive parse rules" for glyphs (Noronha, 2002). Access to Linux codes also means that unnecessary code can be removed and to keep a given program sufficiently small so that it can run on older, "outdated" machines. In the glyphs patch case, the patch, some documentation, utilities and sample files are bundled together in a 100KB package.

A user's "Status-conferral" [9] as a member of the Linux community—"community identification" [10] has also increased Linux's observability. Linux communities are compared with the Red Cross and United Nations (Sibley, 1997). Hars and Ou's survey conducted among OSS programmers (Linux had the highest share) revealed that community identification was a major motivation for 27.8 percent of the respondents — peer recognition for 43 percent.

Trialability

Linux is available for free downloading and use and hence has "unlimited" trialability [11]. It thus fares better than proprietary software on trialability, at least for skilled users. Linux-friendly companies, such as Red Hat, VA Software, and IBM (Lerner and Tirole, 2002), have further 
helped to increase Linux's trialability. For instance, IBM has Linux competency centres across four continents to provide its customers with a hands-on environment to test and deploy Linuxbased solutions.

The externality and spillover effects created by Linux communities and collaborations among them have further improved Linux's trialability. They are helping educational institutions, government agencies, private businesses and individual users worldwide to adopt Linux. For instance, consider, the Israeli Group of Linux Users (IGLU). IGLU organizes "Linux installation parties" several times a year in which less experienced users get installation and other help from knowledgeable and experienced users. IGLU also frequently organizes "Linux dinners" where discussions about Linux take place in the course of a meal.

Added to the above measures are collaborations among OSS promoters and international institutions. UN's Sustainable Development Networking Program (SDNP), for instance, has partnered with such organizations as Corel, Rebel.com, Red Hat, and HP to facilitate the adoption of OSS in developing countries. For instance, Corel Computers is granting multiple licenses to various Linux versions in several languages to SDNP's 40 offices in developing countries (SDNP, 2003).

Discussion, conclusion and implications

This paper analyzed the determinants governing diffusion dynamics for Linux. Linux possesses greater relative advantage than its proprietary competitors but fares worse on complexity and compatibility dimensions. Linux also has a reasonably good performance on observability and trialability, although there is only a weak empirical support for the influence of these two dimensions on technology adoption. So what measures can be taken to improve Linux's perception on these dimensions?

Linux-friendly commercial companies and the Linux community should take measures to further improve Linux's performance on relative advantage. If Linux-friendly commercial companies reduce the prices of their services and products, it helps to increase net benefits to Linux users (Katz and Shapiro, 1986) which helps increase the size of the network [12]. Moreover, although there are very few attacks to systems based on Linux, the number is likely to increase in future. To sustain Linux's low downtime costs, more anti-virus software for Linux-based systems should be developed and made available to users. 
Compatibility issues associated with business partners' technologies have the least influence on governments in developing countries. However, because governments are the biggest single users of hardware and software in most developing countries (Moussa and Schware, 1992; Nidumolu, et al., 1996), their decisions related to operating system can have a powerful secondary compatibility effect. The choice by a government of a proprietary system (such as Microsoft) excludes not only open source operating systems but also other proprietary systems (such as Apple). In a similar vain, a decision to use Linux can yield powerful incentive to use it - even in inappropriate circumstances. It is thus important for governments to focus on both access to resources and on keeping future options open (Kshetri, 2004). Although exclusive statewide contracts with OSS are seldom best, governments should explore areas where deployment of OSS could be more appropriate.

Linux communities, Linux-friendly companies and governments can increase Linux's compatibility by making proprietary systems and Linux more interoperable by the "construction of an adapter" [13]. For instance, the Chinese government has launched its own version of Wine, an open source API (application programming interface) that allows Microsoft applications to function on Linux.

Technological competition rather than price competition (Gandal, 2002) is more critical to improve Linux’s performance on complexity dimension. Particularly, Linux communities and Linux-friendly commercial companies should place more emphasis on improving Linux's simplicity and ease of use compared to other quality dimensions such as accuracy, completeness, features, and structuredness.

Linux's observability can be improved by developing software for small linguistic groups. The engagement of Linux communities in philanthropic activities - such as more intensified assistance to those on the wrong side of the digital divide - would enhance the image of Linux and its communities. Such activities may likely result in higher status-conferral to Linux users and their communities and hence the observability of adoption.

Linux's trilability can be enhanced by increasing support for installing and using the software. For instance, Linux communities and promoters can set up dedicated toll-free numbers for existing and potential users. The centres - opened by Linux-friendly commercial companies and operating like IBM’s Linux competency centres — should also be expanded geographically. 
Finally, international organizations such as the U.N. should increase their collaborative efforts with Linux promoters to intensify support for Linux in developing countries.

About the author

Nir Kshetri is an assistant professor at Bryan School of Business and Economics, The University of North Carolina-Greensboro. Nir holds a Ph.D. in Business Administration from University of Rhode Island; an M.B.A. from Banaras Hindu University (India); and an M.Sc. (Mathematics) and an M.A. (Economics) from Tribhuvan University (Nepal). He also holds undergraduate degrees in Civil Engineering and Physics from Tribhuvan University. Nir's papers have been published in journals such as Foreign Policy, IEEE Software, Electronic Markets, Small Business Economics, Pacific Telecommunications Review, Journal of Asia Pacific Business and International Journal of Cases on Electronic Commerce. He has also contributed chapters to several books including the Encyclopedia of Information Science and Technology (Idea Group, 2005), Indian Telecom Industry — Trends and Cases (ICFAI University Press, 2005), The Internet Encyclopedia (Wiley, 2004); Wireless Communications and Mobile Commerce (Idea Group, 2003); Digital Challenges: Information Technology in the Development Context (Ashgate Publishing, 2003); Architectural Issues of Web-enabled Electronic Business (Idea Group, 2003); and, Internet Marketing (Second edition, Stuttgart, Germany: Schaeffer-Poeschel, 2001). He has also co-authored three textbooks on mathematics and statistics.

\section{Notes}

1. A technology fares better in divisibility dimension if potential users can select features they want and time of use and pay accordingly (Cats-Baril and Jelassi, 1994; Zaltman, et al., 1984).

2. It should be noted that a large proportion of Microsoft and other software used in many developing countries are pirated versions and hence are free to the end users. The trade-related aspects of intellectual property rights (TRIPS) agreement of the World Trade Organization (WTO), however, has obligated developing countries to provide new enforcement tools to combat piracy and to ensure the adequacy of such tools (see Samahon, 2000). Enforcement will be staggered, with the last mandatory compliance being 1 January 2006 for the poorest countries.

3. An 18 September 2003 article in the The Wall Street Journal quotes Symantec Corp.’s findings which indicated that over 4,000 viruses and other malicious programs were launched against Microsoft Windows during the first eight months of 2003, compared to 11 attacks against Unix and Linux for the same period.

4. Katz and Shapiro, 1985, p. 424.

5. Katz and Shapiro, 1994, p. 108. 
6. Also see 'Issues Raised by DARE Critics' at http://breeze.ifas.ufl.edu/ppt/18, accessed 15 January 2004.

7. We have some empirical evidence to support this argument. For instance, more than eight years ago a study found that organizations from developed countries accepted new suppliers only if they could demonstrate an electronic data interchange (EDI) capability (Schware and Kimberley, 1995). Similarly, pressure from U.S.-based multinationals such as WalMart and J.C. Penney require their foreign suppliers to transact on the Internet. The suppliers, mainly from developing Asian countries, adopted the Internet because of such pressure.

8. Smith and Andrews (1995) found that customer certainty mediates customer fit (or Roger's compatibility). We thus argue that uncertainty results in reduced compatibility. We thank a reviewer for pointing out this connection.

9. Rogers, 1995, p. 246. In the case of a cellular phone, for instance, Rogers (1995: pp. 245-246) suggests that status-conferral to potential buyers increases its observability.

10. Hars and Ou, 2002, p. 28.

11. As mentioned in note 2, so far, endemic piracy has resulted in unlimited trialability of proprietary operating systems as well. Full compliance with TRIPS is expected to reduce the proportion of pirated software and hence the attractiveness of Linux's unlimited trialability.

12. For instance, in 2003, the prices of Suse Linux 9.0 Professional and Red Hat Linux 9.0 Personal were US\$64.99 and US\$39.88 respectively (see http://www.amazon.com/exec/obidos/ASIN/B00008Y1CC/ref\%3Dnosim/internationalist3120/104-2721189-6938328, accessed 15 January 2004).

13. Katz and Shapiro, 1985, p. 434.

\section{References}

Dennis A. Adams, Nelson R. Ryan and Peter A. Todd, 1992. "Perceived usefulness, ease of use, and usage of information," MIS Quarterly, volume 16, number 2, pp. 227-247.

Paul Ammann, 2002. "The greater benefits of Open Source software," Newsforce (29 June), at http://emoglen.law.columbia.edu/CPC/archive/AdTI/1940237.shtml\%3Ftid=11.html., accessed 29 July 2005.

A. Applewhite, 2003. "Should governments go Open Source?" IEEE Software, volume 20, number 4, pp. 88-91. 
William M. Bulkeley, 2003. "Technology (a special report): free software — out of the shadows: Open-Source software is not only becoming acceptable; it’s also becoming a big business," Wall Street Journal (31 March), p. R6.

Business Week, 2003. "The Linus uprising how a ragtag band of software geeks is threatening Sun and Microsoft — and turning the computer world upside down," Business Week (3 March), pp. $78-84$.

Angel J. Cat, 2001. "Standardizing Linux — It’s a good thing," Business Communications Review, volume 31, number 1, pp. 64-67.

William L. Cats-Baril and Tawfik Jelassi, 1994. "The French videotex system Minitel: A successful implementation of a national information echnology infrastructure," MIS Quarterly, volume 18, number 1, pp. 1-20.

CCIANet, 2003. "Microsoft monopoly represents national security risk, say Internet security experts," CCIANet (24 September), http://www.ccianet.org/press/03/0924.pdf, accessed 15 January 2004.

Jonathan Coppel, 2000. "E-commerce: Impacts and policy challenges," Organization of Economic Cooperation and Development (OECD), Economics Department Working Paper, number 252, at http://www.olis.oecd.org/olis/2000doc.nsf/c5ce8ffa41835d64c125685d005300b0/c12568d1006e 03f7c12569070052efe3/\$FILE/00079760.PDF, accessed 24 December 2000.

F.D. Davis, 1989. "Perceived usefulness, perceived ease of use and user acceptance of information echnology," MIS Quarterly, volume 13, number 3, pp. 319-339.

Andre de Palma, Luc Leruth and Pierre Regibeau, 1999. "Partial compatibility with network externalities and double purchase," Information Economics and Policy, volume 11, number 2, pp. 209-227.

The Economist, 2003. "The ponytail versus the penguin," (22 May), p. 70, and at http://www.economist.com/people/displayStory.cfm?story_id=1795930, accessed 29 July 2005.

Europemedia, 2003. "Microsoft memo suggests institutional discount strategy aimed o block Linux," (19 May), p. 1.

David Ford, Lars-Erik Gadde, Hakan Hakansson, Anders Lundgren, Ivan Snehota, Peter Turnbull and David Wilson, 1998. "How companies relate to each other," In: David Ford, LarsErik Gadde, Hakan Hakansson, Anders Lundgren, Ivan Snehota, Peter Turnbull and David Wilson. Managing business relationships. New York: Wiley, pp. 17-40.

G. Frizelle, 1998. "The management of complexity in manufacturing," at http://www.businessintelligence.co.uk/reports/complexity/default.asp, accessed 29 July 2005. 
Neil Gandal, 2002. "Compatibility, standardization, and network effects: Some policy implications," Oxford Review of Economic Policy, volume 18, pp. 80-91.

Hubert Gatignon and Thomas S. Robertson, 1985. "A propositional inventory for new diffusion research," Journal of Consumer Research, volume 11, pp. 849-867.

Rishab Aiyer Ghosh. 2003. "Licence fees and GDP per capita: The case for open source in developing countries," First Monday, volume 8, number 12 (December), at http://firstmonday.org/issues/issue8_12/ghosh/, accessed 29 July 2005.

G. Pierre Goad and Lorien Holland, 2000. "China joins Linux bandwagon," Far Eastern Economic Review (24 February), pp. 8-12.

Douglas F. Gray, 2000. "Low cost gives Linux global appeal, say supporters at Comdex," InfoWorld (14 November), at http://www.infoworld.com/articles/hn/xml/00/11/14/001114hnlinglob.html, accessed 29 July 2005.

Alexander Hars and Shaosong Ou, 2002. "Working for free? Motivations for participating in Open-Source projects," International Journal of Electronic Commerce, volume 6, number 3, pp. 25-39.

Barbara B. Jackson, 1985. Winning and keeping industrial customers: The dynamics of customer relationships. Lexington, Mass.: Lexington Books.

E. Karahanna, D.W. Straub and N.L. Chervany, 1999. "Information technology adoption across time: A cross-sectional comparison of pre-adoption and post-adoption beliefs," MIS Quartery, volume 23, number 2, pp. 183-213.

N.K. Katyal, 2003. "Digital architecture as crime control," Yale Law Journal, volume 112, number 8, pp. 2261-2289.

M. Katz and C. Shapiro, 1994. "Systems competition and network effects," Journal of Economic Perspectives, volume 8, number 2, pp. 93-115.

M. Katz and C. Shapiro, 1986. "Technology adoption in the presence of network externalities," Journal of Political Economy, volume 94, pp. 822-841.

M. Katz and C. Shapiro, 1985. "Network externalities, competition and compatibility," American Economic Review, volume 75, number 3, pp. 424-440.

Bruce Kogut and Anca Metiu, 2001. "Open-Source software development and distributed innovation," Oxford Review of Economic Policy, volume 17, number 2, pp. 248-264. 
Nir Kshetri, 2004. "Economics of Linux adoption in developing countries," IEEE Software, volume 21, number 1, pp. 74-81.

Nir Kshetri, 2001. "Determinants of the locus of global e-commerce," EM — Electronic Markets, volume 11, number 4, pp. 250-257.

J. Lerner and J. Tirole, 2002. "Some simple economics of Open Source," Journal of Industrial Economics, volume 50, number 2, pp. 197-234.

L. Loh and Y.-S. Ong, 1998. "The adoption of Internet-based stock trading: A conceptual framework and empirical results," Journal of Information Technology, volume 13, pp. 81-94.

David L. Margulius, 2003. "The real cost of Linux," InfoWorld (1 September), p. 36; see http://www.infoworld.com/infoworld/article/03/08/29/34FElinux_1.html, accessed 29 July 2005.

Donald B. Marron and David G. Steel, 2000. "Which countries protect intellectual property? The case of software piracy," Economic Inquiry, volume 38, number 2, pp. 59-174.

Joseph Menn, 2003. "Microsoft opens Windows to China," Los Angeles Times (1 March); see also

http://www.ebusinessforum.com/index.asp?layout=rich_story\&doc_id=6393\&categoryid=\&chan nelid=1+or+*\&search=china, accessed 29 July 2005.

John D. Mittelstaedt and Robert A. Mittelstaedt, 1997. "The protection of intellectual property: Issues of origination and ownership," Journal of Public Policy and Marketing, volume 16, number 1, pp. 14-25.

G.C. Moore and I. Benbasat, I1991. "Development of an instrument to measure the perceived characteristics of adopting an information technology innovation," Information Systems Research, volume 2, number 3, pp. 192-222.

A. Moussa and R. Schware, 1992. "Informatics in Africa: Lessons from World Bank experience," World Development, volume 20, number 12, pp. 1737-1752.

Sarma R. Nidumolu, Seymour E. Goodman, Douglas R. Vogel and Ann K. Danowitz, 1996. "Information echnology for local administration support: The Governorates Project in Egypt," MIS Quarterly,, volume 20, number 2, pp. 196-224.

Frederick Noronha, 2002. "Indian language solutions for GNU/Linux," Linux Journal (1 November), a http://www.linuxjournal.com/article/6282, accessed 29 July 2005.

L.E. Ostlund, 1974. "Perceived innovation attributes as predictors of innovativeness," Journal of Consumer Research, volume 1 number 2, pp. 23-29.

Bill Parish, 2003. "Other Voices: Feeding Many Mouths," Barron’s (21 April), p. 37. 
Christian Payne, 2002. "On the security of open source software," Information Systems Journal, $12(1), 61-78$.

Matt Pottinger, 2003. "Software firms face setback in China — Proposed rules would force regional governments to use domestic vendors," Wall Street Journal (7 March), p. B5.

Everett M. Rogers, 1995. Diffusion of innovations. Fourth edition. New York: Free Press.

Everett M. Rogers, 1983. Diffusion of innovations. Third edition. New York: Free Press.

Everett M. Rogers, 1962. Diffusion of innovations. New York: Free Press.

T.N. Samahon, 2000. "TRIPS copyright dispute settlement after the transition and moratorium: Nonviolation and situation complaints against developing countries," Law and Policy in International Business, volume 31, number 3, pp. 1051-1175.

Walt Scacchi, 2002. "Understanding the requirements for developing Open Source software," IEEE Proceedings - Software, volume 149, number 1, pp. 24-39, and at www1.ics.uci.edu/ wscacchi/Papers/ New/Understanding-OS-Requirements.pdf, accessed 29 July 2005.

Robert Schware and Paul Kimberley, 1995. "Information technology and national trade facilitation," World Bank, Technical Paper, number 317. Washington D.C.: World Bank, p. 19; see also http://wwwwds.worldbank.org/servlet/WDS_IBank_Servlet?pcont=details\&eid=000009265_396121415572 5, accessed 29 July 2005.

Ed Scannell and Bob Trott, 1999. "Chipping away at Microsoft," InfoWorld (24 May), p. 39; see also http://www.infoworld.com/cgi-bin/displayStory.pl?/features/990524microsoft.htm, accessed 29 July 2005.

Bruce Schneier, 1999. "Open Source and security," Crypto-Gram Newsletter (15 September), at http://www.schneier.com/crypto-gram-9909.html\#OpenSourceandSecurity, accessed 29 July 2005.

Carl Shapiro and Hal R. Varian, 1999. Information rules: A strategic guide to the network economy. Boston: Harvard Business School Press.

Kathleen Sibley, 1997. "Linux: More than an OS, it’s like a religion," Computing Canada, volume 23, number 15 (21 July), pp. 18-19.

SinoCast China Business Daily News, 2003. "Scott McNealy to come to China," SinoCast China Business Daily News (13 March). 
Daniel C. Smith and Jonlee Andrews, 1995. "Rethinking the effect of perceived fit on customers' evaluations of new products," Journal of the Academy of Marketing Science, volume 23 (Winter), pp. 115-124.

Sustainable Development Networking Program (SDNP), 2003. "Sustainable Development Networking Program: Partners," at http://www.sdnp.undp.org/partners/, accessed 15 January 2004.

Lester C. Thurow, 1997. "Needed: A new system of intellectual property rights," Harvard Business Review, volume 75, number 5 (September-October), pp. 95-103.

L.G. Tornatzky and K.J. Klein, 1982. "Innovation characteristics and innovation adoptionimplementation: A meta-analysis of findings," IEEE Transactions on Engineering Management, volume 29, number 1, pp. 28-46.

United Nations Conference on Trade and Development (UNCTAD), 2002. "Good prospects For IT industry In 2003, predicts UNCTAD; Developing world looks to e-business for growth," press release TAD/INF/PR65 (18 November), at http://r0.unctad.org/ecommerce/docs/edr02_en/ecdr02press1.htm, accessed 22 July 2003.

Thomas Tan Tsu Wee, 2003. "Factors affecting new product adoption in the consumer electronics industry," Singapore Management Review, volume 25, number 2, pp. 51-71.

Gene Wilburn, 1997. "Linux: Real-world Unix with an attitude," Computing Canada (6 January), p. 29.

Frederick Williams and David V. Gibson, 1990. Technology transfer: A communication perspective. Newbury Park, Calif.: Sage Publications.

Ming-Wei Wu and Ying-Dar Lin, 2001. "Open Source software development: An overview," IEEE Computer, volume 34, number 6, pp. 33-38.

Gerald Zaltman, Robert Duncan and Jonny Holbek, 1984. Innovations and organizations. Malabar, Fla.: R.E. Krieger. 